\title{
POLÍTICA DE EDUCAÇÃO ESPECIAL: CONSIDERAÇÕES SOBRE PÚBLICO-ALVO, FORMAÇÃO DE PROFESSORES E FINANCIAMENTO
}

\author{
SPECIAL EDUCATION POLICY: CONSIDERATIONS ON TARGET AUDIENCE, \\ TEACHER TRAINING AND FUNDING
}

\author{
POLÍTICA DE EDUCACIÓN ESPECIAL: CONSIDERACIONES SOBRE \\ PÚBLICO-ALVO, FORMACIÓN DE PROFESORES Y FINANCIACIÓN
}

\author{
Eduardo José MANZINI ${ }^{1}$
}

\begin{abstract}
RESUMO: Neste artigo, são discutidas as implicações políticas e financeiras em relação ao público-alvo da educação especial e a formação de professores. O público-alvo da educação especial foi restringido pela politica de 2008. Várias ações puderam ser realizadas: criação das Salas de Recursos Multifuncionais, formação de professores, financiamento do Projeto de Apoio a Educação Especial. Atualmente, uma nova discussão tenta ampliar essa clientela. Porém, duas controvérsias estão presentes: a primeira é que a definição da população atendida parece não se enquadrar em categorias de deficiência determinadas por critérios científicos; a segunda, ao ampliar o público-alvo os recursos financeiros devem ser ampliados. Infelizmente, o momento econômico do país não garante aporte financeiro para concretizar essa mudança. Alguns municípios já estão terceirizando o Atendimento Educacional Especializado para instituições não governamentais. Esse fato está contribuindo para que não sejam realizados investimentos financeiros na escola pública, que poderá se fragilizar nos anos vindouros.
\end{abstract}

PALAVRAS-CHAVES: Educação especial. Politica educacional. Financiamento da educação.

RESUMEN: En este documento, discutimos las implicaciones políticas y financieras en las relaciones entre el público de la educación especial y la formación docente. El público de educación especial se ha restringido por la política de educación especial de 2008. Se podrían llevar a cabo varias acciones: creación de Salas de Recursos Multifuncionales, capacitación docente, financiación del Proyecto de Apoyo a la Educación Especial. Actualmente, una nueva discusión intenta alterar esta clientela. Sin embargo, existen dos controversias: la primera es que la definición de población atendida no parece enmarcarse en categorías de discapacidad determinadas por criterios científicos; el segundo, al expandir el público, los recursos financieros deben expandirse. Desafortunadamente, el momento económico del país no garantiza la contribución financiera para lograr este cambio. Algunos municipios ya subcontratan el Servicio Educativo Especializado a instituciones no gubernamentales. Este hecho está contribuyendo para que no se realicen inversiones financieras en la escuela pública, que podría debilitarse en los años venideros.

PALABRAS CLAVE: Educación especial. Política educativa. Financiamiento educativo.

${ }^{1}$ Universidade Estadual Paulista (UNESP), Marília - SP - Brasil. Docente do Departamento de Educação Especial e do Programa de Pós-Graduação em Educação. Líder do Grupo de Pesquisa Deficiências Físicas e Sensoriais, bolsista produtividade 1B pelo CNPq. ORCID: <https://orcid.org/0000-0002-71578227>. E-mail: eduardo.manzini@unesp.br

RPGE- Revista on line de Política e Gestão Educacional, Araraquara, v. 22, n. esp. 2, p. 810-824, dez., 2018. ISSN: 1519-9029. DOI: 10.22633/rpge.unesp.v22.nesp2.dez.2018.11914 
ABSTRACT: In this paper, we discuss the political and financial implications in the relationships between the target audience of special education and teacher training. The target audience of special education was restricted by the special education policy. Several actions could be carried out: creation of Multifunctional Resources Classes Rooms, teacher training, financing of the Special Education Support Project. Currently, a new discussion tries to alter this clientele. However, two controversies are present: the first is that the definition of the population served does not seem to frame into categories of disability determined by scientific criteria; the second, when expanding the target audience, financial resources must be expanded. Unfortunately, the country's economic moment does not guarantee the financial contribution to achieve this change. Some municipalities are already outsourcing the Specialized Educational Service to non-governmental institutions. This fact is contributing to the fact that no financial investments are made in the public school, which may become fragile in coming years.

\section{KEYWORDS: Special education. Educational policy. Educational funding.}

\section{Introdução}

As discussões atuais em relação às políticas da área de Educação Especial têm se direcionado, em uma de suas vertentes, para a ampliação da clientela atendida no campo educacional. Desde 2008, as diretrizes da Política Nacional de Educação Especial na Perspectiva da Educação Inclusiva (BRASIL, 2008) indicavam que o alvo seria os estudantes com deficiência, transtornos globais do desenvolvimento e altas habilidades/superdotação. Essa clientela foi, e continua sendo denominada como o público-alvo ${ }^{2}$ da Educação Especial.

\section{Público-alvo da educação especial}

A necessidade de definir quem é a clientela de um determinado tipo de serviço é importante para a provisão do aporte financeiro para que as necessidades dessa população possam ser atendidas. Esse é, então, um requisito de qualquer política pública, seja na Saúde, Educação ou Previdência Social. Também é necessário que haja um levantamento de dados demográficos dessa população para que o aporte financeiro atinja ao objetivo dessa política. Sabendo do número de pessoas que poderão ser

\footnotetext{
${ }^{2}$ Apesar de passados quase 10 anos do uso dessa nomenclatura, ainda é possível encontrar textos de autores, e, infelizmente, legislações oficiais, que grafam erroneamente essa expressão. De acordo com a língua portuguesa, a expressão possui hífen. A palavra alvo, quando precedida de outro substantivo, precisa de hífen (HOUAISS, 2018). Como exemplos: município-alvo; língua-alvo; aluno-alvo; estudantealvo. Além disso, possui uma variação quando utilizada no plural: alunos públicos-alvo (VOLP, 2009; MICHAELIS, 2018; HOUAISS, 2018) ou alunos públicos-alvos (HOUAISS, 2018). Por entender que se trata de um único público da Educação Especial, com identidade própria, é possível usar a expressão no plural da seguinte forma: alunos do público-alvo, que gramaticalmente está correta e que irá ser utilizada neste texto.
} 
beneficiadas por uma determinada política pública, o planejamento econômico pode ser mais acertado.

Porém, nem sempre, o governo possui um índice de identificação de estudantes que garanta, de forma mais precisa, qual a porcentagem de estudantes que poderão ser atendidos pela área de Educação Especial. Os dados estatísticos oficiais sobre matrículas de estudantes com deficiência podem ser antagônicos e, de um ano para outro, a clientela da Educação Especial pode simplesmente desaparecer, por exemplo, do Ensino Fundamental I e II para o Ensino Médio, sem que se perceba aumento de matrículas em instituições especializadas (informação verbal) ${ }^{3}$. Portanto, há grande evidência de que esses alunos devem ter saído da escola, fenômeno estudado como evasão escolar.

A evasão escolar é um fenômeno previsto e tem sido mensurada nos relatórios de monitoramento do Plano Nacional de Educação. Como previsto na Meta 3, o desafio é a universalização do atendimento aos adolescentes de 15 a 17 anos. O relatório apresenta uma clara conclusão sobre a dificuldade para alcançar essa meta:

[...] Cerca de 900 mil adolescentes que estão fora da escola e não concluíram o ensino médio foram matriculados no início de sua trajetória escolar na idade adequada, mas sofreram percalços nessa trajetória que os impediram de permanecer até a conclusão (BRASIL, 2018a, p. 72).

Se, por um lado, os dados estatísticos ajudam a mensurar fenômenos como a evasão escolar, por outro, já havia, em 2006, uma séria dificuldade em definir características da população a ser atendida pela área da Educação Especial. Antes mesmo da promulgação das diretrizes políticas de 2008, o primeiro documento norteador para a implantação das Salas de Recursos Multifuncionais (ALVES et al. 2006) apontava que um público a ser atendido por esse serviço seria, também, estudantes com déficit de atenção e dislexia, documento que não está mais disponível no site do MEC (MANZINI, 2012).

Uma mesma sala de recursos, organizada com diferentes equipamentos e materiais, pode atender, conforme cronograma e horários, alunos com deficiência, altas habilidades/superdotação, dislexia, hiperatividade, déficit de atenção ou outras necessidades educacionais especiais (ALVES et al, 2006, p. 14).

3 Informação verbal de dados apresentados por Rosângela Gavioli Prieto durante o II Congresso Brasileiro de Educação Especial e Inclusiva e XIV Jornada de Educação Especial, em maio de 2018, em Marília, UNESP. 
Como então identificar e definir, por meio de um censo, estudantes para serem atendidos pela Educação Especial, a exemplo dos estudantes com dislexia, ou com necessidades educacionais especiais como estudantes com dificuldades de aprendizagem?

A definição de estudantes com dificuldades de aprendizagem não é só um problema da realidade brasileira. Isto também foi questionado por pesquisadores de Portugal (CORREIA, 2007) quase na mesma época cronológica da publicação das Diretrizes da Educação Especial na Perspectiva da Educação Inclusiva no Brasil.

Correia (2007) discutiu o conceito de dificuldade de aprendizagem pensando na política de Portugal e já argumentava que, para elaborar uma definição de dificuldade de aprendizagem, seria preciso que esse tema fosse enfocado conceitualmente, para que, então, esse conceito fosse operacionalizado. Para o autor, um primeiro passo é um consenso entre políticos, professores, pesquisadores, médicos, pais etc. Para ele, a história tem mostrado que uma das dificuldades em estabelecer uma definição de Dificuldade de Aprendizagem esbarrou na vasta nomenclatura criada para definir esse fenômeno: lesão cerebral, disfunção cerebral mínima, hiperatividade, dificuldades perceptivas, dificuldades de linguagem, dislexia, distúrbios de aprendizagem psiconeurológicos.

No contexto brasileiro, a história não foi diferente. Por exemplo, a disfunção cerebral mínima foi um conceito difundido há mais de 40 anos, cujo tratamento ocorreu por meio de medicamentos para atingir a uma parcela da população que não apresentava ganhos educacionais (LEFÉVRE, 1975). O problema consistiu em saber onde se localizava, no cérebro, a tal disfunção. O mesmo ocorreu, no passado, com a identificação de estudantes com deficiência intelectual. Muitos estudantes das classes especiais para deficiência mental, nomenclatura da época, possuíam, na realidade, um atraso na aprendizagem (DENARI, 1984).

Ao propor que o público-alvo da Educação Especial seja redefinido, é preciso indicativos de quando isso irá custar em termos de investimento para atender a essa população.

Em 2008, ao definir quem seriam os estudantes a serem atendidos pela Educação Especial, havia clareza de que outras secretarias do MEC arcariam com gastos como merenda, transporte, alfabetização, comuns a todos os alunos do sistema educacional. O suporte financeiro para a Secretaria de Educação Especial - nome da época - foi, então, destinado a um público que antes era mais diverso e numeroso, cuja nomenclatura foi 
originária da tradução da Declaração de Salamanca: necessidades educativas especiais. Posteriormente, a expressão foi reformulada, por pesquisadores brasileiros, para necessidades educacionais especiais. A grande dificuldade foi separar, dessa categoria, aqueles estudantes rotulados com necessidades educacionais especiais, daqueles decorrentes de um processo de construção social da deficiência, ou seja, estigmatizados e rotulados pela deficiência do próprio sistema educacional em prover ensino para esses estudantes.

Dentro desse contexto é que o público-alvo foi restringido para que os aportes financeiros pudessem dar suporte aos objetivos pretendidos. Outros tipos de necessidades educacionais especiais ficariam, então, a cargo do sistema educacional providos por outras Secretarias do MEC.

A partir de 2008, muitos investimentos foram realizados para esse público-alvo. O próprio abastecimento com recursos e equipamentos de Tecnologia Assistiva para a Sala de Recursos Multifuncionais foi direcionado para esses estudantes do público-alvo da Educação Especial.

As Salas de Recursos Multifuncionais foram classificadas para um determinado público a ser atendido. Nas salas do Tipo I, havia uma variedade de recursos e equipamentos para atender a estudantes com deficiências, que era diferente do Tipo II, que incorporava recursos e equipamentos da sala do Tipo I e ampliava com equipamentos e recursos para estudantes cegos ou com baixa visão. Essa concepção demonstra a necessidade de prover equipamentos e recursos cujo aporte financeiro seja necessário. As Salas de Recursos Multifuncionais do Tipo II são mais caras e menos numerosas, porém, sabe-se, estatisticamente, que o número de estudantes cegos e com baixa visão é menor que o número de estudantes com deficiência intelectual, cujos recursos e equipamentos podem ser encontrados na sala do Tipo I e II. Com certeza, ainda há uma grande discussão sobre quais deveriam ser os recursos e equipamentos necessários para as salas, discussão que precisa avançar para que, de forma mais científica, seja possível melhor definir os gastos necessários para incorporar novos recursos e equipamentos, como estava previsto no plano de implantação desse serviço (MANZINI; GLAT, 2016).

No momento atual, existe a discussão para a ampliação do público-alvo da Educação Especial (BRASIL, 2018b): 
Estudantes cuja participação plena e efetiva nas atividades escolares é obstruída pela interação entre as barreiras (urbanísticas, arquitetônicas, atitudinais, tecnológicas, nos transportes e nas comunicações e informações) e os impedimentos individuais de longo prazo de natureza: Intelectual; Mental; Comportamental, Social, Comunicacional e de Linguagem; Visual; Auditiva; Multisensorial ${ }^{4}$; Física; Múltipla (grifo nosso).

Em alguma medida, é possível identificar que a categoria Mental deve ter sido abstraída da lei da Inclusão, que define a pessoa com deficiência:

III - pessoa com deficiência: aquela que tem impedimento de longo prazo de natureza física, mental, intelectual ou sensorial, o qual, em interação com uma ou mais barreiras, pode obstruir sua participação plena e efetiva na sociedade em igualdade de condições com as demais pessoas (BRASIL, 2015, grifo nosso).

A categoria Mental pode ser transportada para categorias advindas da psicologia ou psiquiatria. Sua definição nos meios educacionais é uma incógnita. Necessitaria ela de serviços de Educação Especial ou de Serviços de outra natureza? Como os de psicologia?

Se, por um lado, parecer haver uma confusão conceitual em definir a categoria intitulada Mental, por outro, estudantes com "impedimentos individuais de longo prazo" de natureza "comunicacional ou linguagem" estão sendo contemplados com recursos e equipamentos das Salas de Recursos Multifuncionais. Por exemplo, alunos acometidos por paralisia cerebral podem carecer de serviços da área de Comunicação Alternativa. Softwares livres para construção de pranchas de comunicação têm sido utilizados por professores que trabalham nas Salas de Recursos Multifuncionais. O mesmo se refere a alunos com deficiência intelectual que apresentam severos comprometimentos de comunicação ou em linguagem. Portanto, parece estranho criar categorias que, cientificamente, já têm sido discutidas e fazem para da população de estudantes atendidos nas Salas de Recursos Multifuncionais.

Voltando, então, para as considerações de Correia (2007), uma categoria nova necessita ser discutida por uma comunidade: pesquisadores, políticos, professores, pais, dentre outros, para que haja um consenso numa definição clara, precisa, e que possa ser aferida pelo censo demográfico afim de que haja um aporte financeiro para o atendimento.

\footnotetext{
${ }^{4}$ A citação direta do documento do MEC apresenta essa palavra grafada incorretamente, que deveria ser: multissensorial.
} 
Independente de ser contra ou a favor dessa mudança, é preciso avaliar se essa alteração trará benefícios futuros para os estudantes-alvo da política.

Com os cortes e congelamento dos gastos da educação nos dois últimos anos, e com as recorrentes manifestações da Capes e do $\mathrm{CNPq}$ em relação à restrição orçamentária, há uma forte evidência da falta de recursos financeiros. Seria, então, essa ampliação apropriada para o momento econômico e político atual? Em termos políticos, é necessário questionar: as alterações atualmente projetadas seriam interessantes a quem? Visto que os recursos estão se tornando insuficientes para o atual público-alvo da Educação Especial, qual será a projeção futura traçada por uma nova política?

\section{Estudantes do público-alvo da educação especial e formação de professores}

Quando se iniciaram, no Brasil, as discussões em torno do tema inclusão escolar $^{5}$, havia um grande receio em relação à formação dos professores para atender aos alunos com deficiência.

Naquela época - como atualmente ainda é possível ouvir - prevaleciam duas controvérsias, um questionamento e uma afirmação: 1) como realizar a inclusão escolar se os profissionais da educação não estão preparados para ela? 2) a inclusão se refere a um processo e não está pronto a priori, portanto, ninguém pode ser preparado antes de passar por esse processo. Independente de responder a essas controvérsias, houve o financiamento por meio do Proesp - Programa de Apoio a Educação Especial, com o objetivo de pesquisar e formar pesquisadores para o tema em foco.

Na segunda versão do edital Proesp, em 2003, foi concedido financiamento a pesquisadores de Universidades Públicas com o objetivo de realizar a formação de profissionais para trabalhar com a inclusão em projetos educacionais e de pesquisa para serem iniciados em 2004. A primeira meta era que esses pesquisadores pudessem realizar pesquisas e formação de docentes em prol da inclusão.

Após dois anos de implantação dos projetos, foi possível realizar o $1^{\circ}$ Encontro Nacional do Programa de Educação Especial (Proesp), nos dias 12 e 13 de junho de 2006, em Porto Alegre (RS), para avaliar os resultados desse programa, publicados, posteriormente, pelo MEC (BRASIL, 2007). Os resultados sensibilizaram os representantes da Capes, presentes na reunião, que se comprometeram a utilizar

\footnotetext{
${ }^{5}$ A utilização da expressão inclusão escolar, neste documento, segue conceitualmente o que é defendido
} por Mendes (2018).

RPGE- Revista on line de Política e Gestão Educacional, Araraquara, v. 22, n. esp. 2, p. 810-824, dez., 2018. ISSN: 1519-9029. 
recursos de fundos perdidos para novas versões do Proesp nos anos posteriores (BRASIL, 2009).

Ao mencionar esse acontecimento, é necessário frisar o que está subjacente a ele: qualquer política que deseja implantar algo novo necessita de ampla discussão e avaliação, para averiguar se as metas estão sendo atingidas e se os aportes financeiros estão suprindo as necessidades dessa implantação. Essa parece ter sido esta uma das características dos programas implantados em torno das diretrizes políticas da Educação Especial em 2008 e antes dela.

Outro ponto importante a ser mencionado se refere ao grupo de trabalho que discutiu e elaborou o documento das diretrizes de 2008: todos os membros do grupo de trabalho eram oriundos de renomadas universidades públicas, eram os coordenadores dos Projetos do Proesp, e atuantes em área distintas da Educação Especial, como surdez, deficiência intelectual, deficiência física, altas habilidades/superdotação, dentre outras. Portanto, profissionais e pesquisadores da área de Educação Especial com características que imputaram às discussões um caráter científico.

Esse caráter científico mobilizou os membros grupo a escrever, pesquisar e a publicar sobre o tema dos próprios projetos. Além disso, um produto que poderia ser mensurável eram as dissertações e teses produzidas pelos estudantes de mestrado ou doutorado que usufruíram de bolsas de pesquisa. Tendo como foco esses produtos finais, foi possível realizar uma pesquisa para investigar quais tinham sido os ganhos científicos com os projetos do Proesp (MANZINI, 2011). A pergunta geradora do estudo foi: com o tipo de conhecimento produzido pelas pesquisas, está sendo possível avançar no conhecimento sobre inclusão escolar? A amostra consistiu em descrever a avaliar todos os projetos financiados no estado de São Paulo. Quatro universidades que receberam financiamento para realizar os projetos fizeram para parte da amostra. Para realiza o estudo, os produtos finais dos projetos foram analisados: as dissertações e teses produzidas, no período do projeto, e que identificaram claramente, nos trabalhos de conclusão do curso, o financiamento recebido. Foram identificadas 27 dissertações e teses, cuja análise recaiu sobre os produtos. Nessa análise não foram enfocadas as instituições que as desenvolveram, mas somente os produtos. Ao analisar os resultados, emergiram cinco categorias: 1) pesquisas que apresentaram generalização e aplicação imediata dos resultados; 2) pesquisas que apresentaram resultados imediatos para um grupo específico de participantes; 3) pesquisas descritivas com achados inovadores; 4) pesquisas de intervenção com achados inovadores; 5) pesquisas descritivas que 
corroboraram outras pesquisas. Na Tabela 1 encontra-se a porcentagem aferida em cada uma dessas categorias.

Tabela 1 - Distribuição dos tipos de conhecimento produzido pelas pesquisas

\begin{tabular}{lcc}
\hline Tipos de conhecimento & $\mathrm{n}$ & $\%$ \\
\hline Generalização e aplicação imediata dos resultados & 10 & 37,04 \\
Resultados imediatos para um grupo específico de participantes & 8 & 29,63 \\
Pesquisas descritivas com achados inovadores & 4 & 14,81 \\
Pesquisas de intervenção com achados inovadores & 3 & 11,11 \\
Pesquisas descritivas que corroboram outras pesquisas & 2 & 7,41 \\
\hline Total & 27 & 100,00 \\
\hline
\end{tabular}

Fonte: Manzini (2011, p. 65)

Os dados apresentados na Tabela 1 indicam que somente dois, dos 27 trabalhos de conclusão, referiram-se a pesquisas descritivas que corroboraram outras pesquisas já realizadas anteriormente. Foi possível concluir que os estudos realizados com o financiamento do Proesp avançaram em relação aos conhecimentos sobre a inclusão, inclusive como o uso de metodologias pouco utilizadas no campo da educação, que serviram de subsídio para obter os resultados (MANZINI, 2011).

Com certeza, o Proesp não iria conseguir a formação de pesquisadores e profissionais da Educação Especial para suprir a todas as necessidades em relação à inclusão escolar, apesar de todo o esforço depreendido e dos resultados alcançados.

Não há dúvida de que nas Diretrizes de 2008, ao referir-se a formação do professor de Educação Especial não explicitou claramente como ela deveria ser realizada (MANZINI, 2012).

No ano seguinte da publicação da Política Nacional de Educação Especial na Perspectiva da Educação Inclusiva, foi publicada a Resolução 04/2009 do CNE-CEB (BRASIL, 2009), que também não avançou em relação à formação de professores para atender a estudantes com deficiência. Esse ponto foi também comentado por Baptista (2011, p. 64), enfatizando que a formação do professor responsável pelo Atendimento Educacional Especializado, indicada pela Resolução, era bastante genérica: “o professor deve ter formação inicial que o habilite para o exercício da docência e a formação específica para a Educação Especial” (Art. 12).

A falta de formação para trabalhar com alunos com deficiência dentro da escola ainda é um dado constantemente coletado e relatado por pesquisadores na formação inicial e na formação continuada. 
Ao realizar uma revisão bibliográfica de artigos publicados sobre o tema inclusão escolar no Brasil na perspectiva de professores, Silva e Carvalho (2017) mencionaram que os artigos e publicações indicam a carência de oferecimento de cursos de capacitação sobre a inclusão, principalmente se referindo ao Estado. Quando oferecidos, existem críticas sobre a inadequação e insuficiência dos conteúdos em relação a uma prática efetiva. Essas críticas se referem não somente em relação aos professores, mas também em relação aos demais profissionais que compõem a equipe de Educação Inclusiva.

Porém, não é somente na formação continuada que se questiona a ausência de formação que professor deve possuir para trabalhar com estudantes com deficiência. Esse fato também ocorre na formação inicial.

Os mesmos autores, ao analisarem a formação inicial, por meios das publicações, também indicaram carência na formação do professor para lidar com estudantes com necessidades educacionais especiais (nomenclatura utilizada pelos autores) e, seja referente ao conhecimento teórico ou de atuação prática (SILVA; CARVALHO, 2017).

Outro ponto importante a ser discutido é se a política está atingindo o objetivo pretendido. A política de educação especial teve como meta o atendimento ao aluno com deficiência dentro da escola comum, oferecendo acesso. Os dados do Relatório do $2^{\circ}$ ciclo de Monitoramento das Metas do Plano Nacional de Educação (BRASIL, 2018a) apresentam informações interessantes que podem ser observadas no Gráfico 1.

Gráfico 1 - Percentual da população de 4 a 17 anos de idade com deficiência, TGD e altas habilidades ou superdotação em classes comuns da educação básica, por sexo - Brasil - 2009-2017

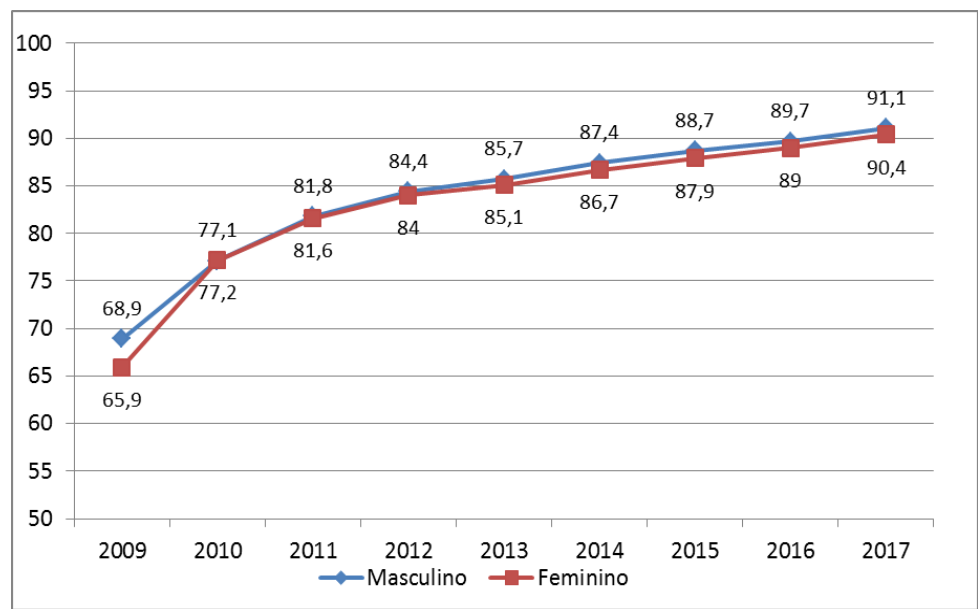

Fonte: BRASIL (2018a) 
Os dados apontaram que, considerando a população de 4 a 17 anos de idade com deficiência, TGD e altas habilidades ou superdotação matriculados em classes comuns da educação básica, havia, em 2009, 65,9\% estudantes do sexo feminino e 68,9\% do sexo masculino. Esses dados modificaram-se em 2017, indicando que estavam matriculados $90,4 \%$ de estudantes do sexo feminino e 91,1 do sexo masculino.

Portanto, é possível vislumbrar o aumento das matrículas nesse período. Assim, a manutenção de uma política pública se manifesta em investimento, que pode e deve ser constantemente avaliada.

Dados do mesmo relatório apontam que:

Houve um aumento de alunos que compõem o público-alvo da educação especial em classes comuns em todas as grandes regiões e UFs entre 2009 e 2011, chegando a atingir aproximadamente 40,0 p.p. no Espírito Santo e em Pernambuco. [..] Em 2017, o percentual de alunos que são público-alvo da educação especial em classes comuns aumentou em todas as redes, atingindo $97,4 \%$ nas estaduais, $96,6 \%$ nas municipais, $82,1 \%$ nas federais e $47,6 \%$ nas privadas (BRASIL, 2018a, p. 91).

Esses dados permitem concluir que está havendo o acesso desses estudantes nas classes comuns.

Infelizmente, os dados não nos informam se estes estudantes estão aprendendo ${ }^{6}$ e nem se a formação dos professores desses estudantes está sendo suficiente para eu isso ocorra. Não há dados estatísticos sobre a formação de professores para atender a inclusão escolar. Uma série de pesquisas tem demonstrado que essa formação ainda não atingiu um nível de qualidade desejada pela política (MENDES; CIA; VALADÃO, 2015).

\section{Estudantes do público-alvo da educação especial, formação de professores e financiamento}

As informações apresentadas neste ensaio apontam para argumentos que tentaram demonstrar que uma política pública de educação especial, que visa à inclusão escolar, necessita, além de definir seu público-alvo, subsidiar a formação de professores para o ensino comum e para o Atendimento Educacional Especializado. Portanto, é necessário suporte financeiro em ambas as frentes.

${ }^{6}$ Em relação a esse tema, brilhante exposição foi realizada pela profa. Dra. Rosangela G. Prieto durante o Fórum de Educação Especial Inclusiva e que ocorreu na UFES, Vitória - ES, entre os dias 17 e 20 de setembro de 2018. 
No Brasil, a Federação repassa, para os estados e municípios, verbas para serem destinadas a Educação e Educação Especial, principalmente oriunda do Fundeb.

Especificamente no caso da Educação Especial, há o financiamento para o Atendimento Educacional Especializado, que pode ser realizado no interior das escolas públicas, por meio das Salas de Recursos Multifuncionais, ou por instituições especializadas. Pesquisas recentes têm se debruçado em analisar como esse financiamento tem sido gerido pelos Estados e Municípios (OLIVEIRA; SOBRINHO, 2018; FRANÇA, 2018).

Ao pesquisar sobre as despesas da Educação Especial município de Vitória, estado do Espírito Santo, França (2018) demonstrou que os investimentos com o custeio da Educação Especial, entre 2008 e 2014, foram na proporção de 0,4\% em relação à Educação Infantil e Ensino Fundamental. Já os gastos com capital equivaleram a 0,01\% $(\mathrm{R} \$ 1.619,98)$ e $0,02 \%(\mathrm{R} \$ 3.145,45)$ nos anos de 2009 e 2010 , sendo que não houve investimento de capital nos anos 2009, 2011, 2012, 2013, 2014. Concluem os autores que os valores zerados ou ínfimos, nos anos de 2009 e 2010, indicaram que o município de Vitoria nada ou tão pouco tenha investido em Educação Especial.

Porém, o dado que mais interessa a presente discussão refere-se aos gastos destinados à Formação de Recursos Humanos: nenhum gasto nos anos de 2008, 2009, 2012, 2013 e 2014. Nos anos de 2010, houve um gasto no valor de R $\$ 27.652,47$ e, em 2011, o valor de $\mathrm{R} \$ 2.142,82$. Com certeza, pode-se concluir que quase não houve investimento para a formação continuada dos professores para a inclusão escolar, uma vez que esses gastos referem-se a todos os níveis e modalidades de ensino do município.

Ao tomar como premissa a consideração de que a inclusão se refere a um processo que não está pronto a priori, sendo necessário que o professor e a comunidade escolar passem por esse processo, e se atrelarmos aos dados do financiamento do município pesquisado por França (2018), poder-se-á corroborar os dados identificados no estudo de Silva e Carvalho (2017), quando mencionaram que, na perspectiva dos professores, há ausência de cursos fornecidos pelo Estado para promover a inclusão escolar.

Ainda referindo-se aos gastos públicos com a Educação Especial, Oliveira e Sobrinho (2018) também pesquisaram o financiamento com a Educação Especial no estado do Espírito Santo entre 2012 e 2015. Os dados indicaram que houve um crescimento gradativo no investimento com a Educação Especial, a partir de 2012, passando de $2,58 \%$ a $3,05 \%$ em 2015 . Os autores analisaram onde os valores estavam 
sendo gastos e descobriram que houve uma terceirização do Atendimento Educacional Especializado (AEE), realizado por instituições especializadas:

[...] em síntese, os dados incialmente nos permitem afirmar que a alternativa adotada pelo estado do Espírito Santo em expandir o AEE pela via da terceirização acabou por restringir o investimento direto na escola pública (OLIVEIRA; SOBRINHO, 2018, p. 237).

Dentre os questionamentos apresentados anteriormente neste ensaio, fica evidente que a política de educação especial, na versão de 2008, avançou, e alguns pontos não podem retroceder. Um deles, e talvez o mais importante seja o caráter das diretrizes que aponta a Educação Especial como uma ação complementar ou suplementar à escolarização, e não mais substitutivo ao ensino comum. Apesar de ainda hoje existirem salas especiais e outras modalidades de atendimento em alguns estados brasileiros, havia uma compreensão de que isso ainda fazia parte do processo de organização dos sistemas de ensino, que estavam em processo de mudança. O mesmo se aplicava a algumas instituições especializadas, que modificaram o seu caráter de atendimento se adaptando a política de 2008. Porém, com o suporte financeiro destinado as instituições, via terceirização dos serviços do Atendimento Educacional Especializado pelo Estado, começa a dar mostras que a escola pública pode ficar fragilizadas, pois já está deixando de receber financiamento para custeio e capital.

Parece que esse seria o pior retrocesso: devolver às instituições especializadas, filantrópicas, $\mathrm{o}$ atendimento a essa população fora da escola pública.

\section{REFERÊNCIAS}

ALVES, D. de O. et al. Sala de recursos multifuncionais: espaço para o atendimento educacional especializado. Brasília, DF: SEESP-MEC, 2006.

BAPTISTA, C. R. Ação pedagógica e educação especial: a sala de recursos como prioridade na oferta de serviços especializados. Revista Brasileira de Educação Especial, Marília, v.17, Edição Especial, p.59-76, 2011.

BRASIL. Atualização da política de educação especial. Brasília, DF: MEC, 2018b. PowerPoint, Slides 13-16.

BRASIL. Instituto Nacional de Estudos e Pesquisas Educacionais Anísio Teixeira. Relatório do $2^{\circ}$ ciclo de monitoramento das metas do plano nacional de educação 2018a. Brasília, DF: Inep. 
BRASIL. Ministério da Educação. Secretaria de Educação Especial. Política nacional de educação especial na perspectiva da educação inclusiva. Brasília, DF: MEC, 2008 .

BRASIL. Ministérios da Educação. Ensaios pedagógicos. Brasília, DF: MEC/SEESP, 2007.

BRASIL. Presidência da República. Casa Civil. Subchefia para Assuntos Jurídicos. Lei $\mathbf{n}^{\mathbf{0}}$ 13.146, de 6 de julho de 2015. Institui a Lei Brasileira de Inclusão da Pessoa com Deficiência (Estatuto da Pessoa com Deficiência). Brasília, DF, 2015. Disponível em: http://www.planalto.gov.br/ccivil_03/_ato2015-2018/2015/lei/113146.htm. Acesso em: 10 set. 2018.

BRASIL. Programa de apoio à educação especial - PROESP/2009. Edital nº 01/2009. Brasília, DF: MEC/Capes, 2009.

CORREIA, L. de M. Para uma definição portuguesa de dificuldades de aprendizagem Específicas. Revista Brasileira de Educação Especial, Marília, v. 13, n. 2, p. 155-172, 2007.

DENARI, F. E. Análise dos critérios de encaminhamento de clientela para classes especiais para deficientes mentais educáveis. 1984. Dissertação (Mestrado em Educação Especial) - Universidade Federal de São Carlos, Programa de Pós-Graduação em Educação Especial, São Carlos, 1984.

FRANÇA, M. G. As despesas da educação especial município de Vitória-ES.

Instituições filantrópicas, de natureza privada, especializadas em educação especial. In: VICTOR, S. L.; VIEIRA, A. B.; OLIVEIRA, I. M. de. (Org.). Educação especial inclusiva: conceitualizações, medicalizações e políticas. Campos dos Goytacazes: Brasil Multicultural, 2018. p. 242-259.

HOUAISS. Grande dicionário Houaiss, 2018. Disponível em: https://houaiss.uol.com.br/pub/apps/www/v3-3/html/index.php\#4. Acesso em: 16 set. 2018.

LEFÉVRE, A. B. et al. Disfunção cerebral mínima. São Paulo: Sarvier, 1975.

MANTOAN, M. T. E. (Org.). Em defesa da política nacional de educação especial na perspectiva da educação inclusiva. Campinas: Laboratório de Estudos e Pesquisas em Ensino e Diferença (Leped) da Faculdade de Educação da Universidade Estadual de Campinas (FE/Unicamp), 2018.

MANZINI, E. J. Tipo de conhecimento sobre inclusão produzido pelas pesquisas. Revista Brasileira de Educação Especial. Marília, v. 17, n. 1, p. 53-70, 2011.

MANZINI, E. J. Política de educação especial e a sala de recursos multifuncionais: alguns limites e possibilidades. In: URT, S. da C.; CINTRA, R. C. G. G. (Org.). Identidade, formação e processos educativos. Campo Grande: Life Editora, 2012. p. 181-194. 
MANZINI, E. J.; GLAT, R. Tecnologia assistiva para o público-alvo da educação especial. In: VICTOR, S. L.; JESUS, D. M. de. Educação especial na perspectiva da educação inclusiva: concepções e práticas educativas. Marília: ABPEE, 2016. p.153165.

MENDES, E. G. Sobre alunos "incluídos" ou "da Inclusão": reflexões sobre o conceito de inclusão escolar. In: VICTOR, S. L.; VIEIRA, A. B.; OLIVEIRA, I. M. de. (Org.). Educação especial inclusiva: conceitualizações, medicalizações e políticas. Campos dos Goytacazes: Brasil Multicultural, 2018. p. 58-81.

MENDES, E. G.; CIA, F.; VALADÃO, G. T. (Org.). Inclusão escolar em foco: organização e funcionamento do atendimento educacional especializado. São Carlos: Marquezine \& Manzini, 2015.

MICHAELIS. Dicionário brasileiro da língua portuguesa. São Paulo: Editora Melhoramentos Ltda, 2018. Disponível em:

http://michaelis.uol.com.br/busca? $\mathrm{r}=0 \& \mathrm{f}=0 \& \mathrm{t}=0 \&$ palavra=publico-alvo. Acesso em: 16 set. 2018.

OLIVEIRA, G. M. de; SOBRINHO, R. C. Notas sobre o financiamento público das instituições filantrópicas, de natureza privada, especializadas em educação especial. In: VICTOR, S. L.; VIEIRA, A. B.; OLIVEIRA, I. M. de. (Org.). Educação especial inclusiva: conceitualizações, medicalizações e políticas. Campos dos Goytacazes: Brasil Multicultural, 2018. p. 218-241.

SILVA, N. C.; CARVALHO, B. G. E. Compreendendo o processo de inclusão escolar no Brasil na perspectiva dos professores: uma revisão integrativa. Revista Brasileira de Educação Especial, Marília, v. 23, n. 2, p. 293-308, 2017.

VOLP. Vocabulário ortográfico da língua portuguesa. 5 ed. Academia Brasileira de Letras, 2009. Disponível em: http://www.academia.org.br/nossa-lingua/busca-novocabulario?sid=23. Acesso em: 16 set. 2018.

\section{Como referenciar este artigo}

MANZINI, E. J. Política de educação especial: considerações sobre público-alvo, formação de professores e financiamento. Revista on line de Política e Gestão Educacional, Araraquara, v. 22, n. esp. 2, p. 810-824, dez., 2018. ISSN: 1519-9029. DOI: 10.22633/rpge.unesp.v22.nesp2.dez.2018.11914

Submetido em: 20/08/2018

Aprovado em: 26/10/2018 